\section{PS-187 DEVELOPMENT OF GUT MICROBIOTA: EFFECT OF INTRAPARTUM ANTIBIOTIC PROPHYLAXIS IN BREASTFED TERM NEWBORNS}

${ }^{1} \mathrm{G}$ Tonti, ${ }^{1} \mathrm{~S}$ Martini, ${ }^{1} \mathrm{~L}$ Corvaglia, ${ }^{2}$ Aloisio, ${ }^{2} \mathrm{G}$ Mazzola, ${ }^{2} \mathrm{D}$ Di Gioia, ${ }^{1} \mathrm{G}$ Faldella. ${ }^{1} \mathrm{U} . \mathrm{O}$. Neonatologia E Terapia Intensiva Neonatale, Policlinico Sant'Orsola-Malpighi, Bologna, Italy; ${ }^{2}$ Dipartimento Di Scienze Agrarie, Università Di Bologna, Bologna, Italy

\subsection{6/archdischild-2014-307384.484}

Background and aims Intrapartum antibiotic prophylaxis (IAP) is the most effective strategy to prevent early-onset Group B Streptococcal (GBS) sepsis. A possible role of IAP on neonatal microbiota is assumed. We aimed to evaluate the effect of IAP on the bacterial colonisation of neonatal gut at 7 and 30 days of life (DOL).

Methods Term newborns, vaginally delivered, were recruited at 2 DOL and allocated into four groups. Group 1: infants exclusively breastfed, not exposed to IAP. Group 2: infants partially breastfed (receiving at least $50 \%$ of own mother's milk), not exposed to IAP. Group 3: infants exclusively breastfed, exposed to IAP. Group 4: infants partially breastfed, exposed to IAP. Faecal samples from the enrolled infants were collected at 7 and 30 DOL. The count of Bifidobacteriumspp., assessed by real-time PCR, was compared between the four groups.

Results Fifty-five newborns were recruited: 25 in Group 1, 7 in Group 2, 17 in Group 3, 6 in Group 4. On day 7, IAP-exposed newborns showed a significantly lower count of Bifidobacterium spp. $(\mathrm{p}<0.05)$. Among infants not exposed to IAP, Bifidobacterium spp. count was significantly higher in Group 1 compared to Group 2. On day 30, a significant increase in Bifidobacterium spp. count $(p<0.05)$ compared to day 7 was observed in all groups.

\section{Abstract PS-187 Table}

\begin{tabular}{|l|c|c|}
\hline \multicolumn{3}{|c|}{ Bifidobacterium spp. [Log(CFU/g)] [Median (IQR)] } \\
\hline & Day 7 & Day 30 \\
\hline Group 1 & $7.93(7.40-8.27)$ & $8.69(8.02-9.44)$ \\
\hline Group 2 & $6.56(6.13-7.07)$ & $8.43(7.08-8.51)$ \\
\hline Group 3 & $6.01(5.71-6.47)$ & $8.51(7.83-9.01)$ \\
\hline Group 4 & $6.01(5.59-6.23)$ & $8.68(8.34-9.02)$ \\
\hline
\end{tabular}

Conclusions Early neonatal microbiota is significantly affected by IAP, resulting in a reduced Bifidobacteria colonisation. Breastfeeding promotes the development of bifidogenic flora and possibly contributes to increase Bifidobacterium spp. count in IAPexposed newborns ad 30 DOL.

\section{PS-188 INTESTINO-TROPHIC EFFECTS OF MINIMAL ENTERAL NUTRITION IN PRETERM AND TERM PIGLETS}

${ }^{1} \mathrm{CF}$ Hansen, ${ }^{1} \mathrm{~T}$ Thymann, ${ }^{1} \mathrm{AD}$ Andersen, ${ }^{2} \mathrm{JJ}$ Holst, ${ }^{2} \mathrm{~B}$ Hartmann, ${ }^{3} \mathrm{EBL}$ Heckmann, ${ }^{1} \mathrm{P}$ Sangild. ' Clinical and Experimental Nutrition, University of Copenhagen, Frederiksberg C, Denmark; ${ }^{2}$ Biomedicine, University of Copenhagen, Copenhagen N, Denmark; ${ }^{3} A R L A$ Foods Ingredients, Pediatrics, Viby, Denmark

10.1136/archdischild-2014-307384.485
Background and aims In preterm infants, slow advancement of minimal enteral nutrition (MEN), combined with parenteral nutrition (PN), may be important to increase food tolerance and minimise the risk of necrotizing enterocolitis (NEC). We hypothesised that MEN for five days would increase gut growth and gut hormone release relative to total parenteral nutrition (TPN).

Methods Preterm and term piglets were delivered by caesarean section and fed TPN or PN+MEN (MEN: 0-64 mL bovine colostrum $/ \mathrm{kg} / \mathrm{d}$ ) for five days. From day 5-26 all pigs were fed total enteral nutrition with milk-replacer. Pigs were euthanized at 0,5 or 26 days of age, and gut weight, mucosal volume, Lcell density and plasma levels of GIP and GLP-2 were measured. Results Body weight gain was markedly reduced in preterm vs. term $(\mathrm{P}<0.01)$. Relative to TPN feeding, MEN for 5 days increased relative gut weight, mucosa volume and plasma GLP-2 and GIP in both preterm and term pigs (all $\mathrm{P}<0.05$ ). At 26 days of age, mucosa volume tended to be higher in preterm MEN versus preterm TPN ( $P=0.11)$, whereas relative gut weight, L-cell density and plasma GLP-2 and GIP levels were similar between term/preterm and MEN/TPN.

Conclusion Despite the compromised growth in preterm pigs, the intestine is highly growth-responsive to MEN just after birth in both preterm and term pigs. The effects of MEN on gut dimensions and gut peptide release are minimal after few weeks of full enteral nutrition. MEN provision may be important for short term gut maturation in preterm infants.

\section{PS-189 THE EFFECT OF ENTERAL FEEDING ON REGIONAL CEREBRAL OXYGEN SATURATION IN PRETERM BORN INFANTS}

${ }^{1}$ SJ Kuik, ${ }^{1}$ TE Schat, ${ }^{2}$ AGJFvan Zoonen, ${ }^{1}$ AF Bos, ${ }^{1}$ KNJAvan Braeckel, ${ }^{2}$ JBF Hulscher, ${ }^{1}$ EMW Kooi. 'Neonatology, Beatrix Children's Hospital/University Medical Center Groningen, Groningen, Netherlands; ${ }^{2}$ Pediatric Surgery, University Medical Center Groningen, Groningen, Netherlands

\subsection{6/archdischild-2014-307384.486}

Background Preterm infants do not always demonstrate adequate cerebral vascular autoregulation (CAR). Higher intestinal demands after enteral feeding may compromise cerebral perfusion in these infants. It remains unclear whether enteral feeding influences cerebral perfusion in preterm infants.

Aim To assess the effect of enteral feeding on regional cerebral oxygen saturation $\left(\mathrm{r}_{\mathrm{c}} \mathrm{SO}_{2}\right)$ in preterm infants.

Methods This study was part of a larger prospective cohort study. We used near-infrared spectroscopy to measure $\mathrm{r}_{\mathrm{c}} \mathrm{SO}_{2}$, which is indicative for cerebral perfusion. We measured during two hours on postnatal days 2-5, 8, 15, 22, 29, and 36. Feeding times were manually recorded. We used multi-level analyses to compare preprandial $\mathrm{r}_{\mathrm{c}} \mathrm{SO}_{2}$ values to postprandial $\mathrm{r}_{\mathrm{c}} \mathrm{SO}_{2}$ values, both10-30 min and 30-60 min after feeding.

Results We included 29 preterm infants with a median GA of $28+1 / 7$ (range $25+1 / 7-30+4 / 7$ ) weeks, and a median birth weight of 1025 (range 580-1495) grams. Compared to preprandial values, we found increased postprandial $\mathrm{r}_{\mathrm{c}} \mathrm{SO}_{2}$ values $10-30$ min after feeding (mean[SD]: from 67\%[15] to 71\%[13], $\mathrm{p}=$ 0.014 ), and 30-60 min after feeding (mean[SD]: from 67\%[15] to $73 \%[14], \mathrm{p}=0.000$ ) on day 8 . We observed a trend of decreased $\mathrm{r}_{\mathrm{c}} \mathrm{SO}_{2}$ values $30-60 \mathrm{~min}$ postprandial compared to 